\title{
Hubungan antara Komitmen Organisasi dan Budaya Organisasi dengan Kinerja Guru SD Metta Maitreya Pekanbaru
}

\author{
Yadi Sutikno ${ }^{1}$ Sonika $^{2}$, Rida Jelita ${ }^{3}$ \\ 1,2,3 Program Studi Pendidikan Keagamaan Buddha, Sekolah Tinggi Agama Buddha Maitreyawira, Indonesia
}

\begin{tabular}{l}
\hline \multicolumn{1}{c}{ INFO ARTIKEL } \\
\hline Riwayat Artikel: \\
Diterima: $24-09-2020$ \\
Disetujui: $25-09-2020$ \\
Diterbitkan: $31-12-2020$
\end{tabular}

\section{Kata kunci:}

Komitmen Organisasi

Budaya Organisasi

Kinerja Guru

\section{Alamat Korespondensi:}

\section{ABSTRAK}

Abstract: This research is motivated by the teacher's performance at SD Metta Maitreya which is still classified as not professional, has a score below the KKM, and a lack of organizational commitment to school teachers, as well as a lack of responsibility for teachers in work. Therefore, this study aims to determine the relationship between organizational commitment and organizational culture with the performance of teachers at SD Metta Maitreya Pekanbaru. The research method used is a survey method with correlational techniques. The study population was 24 teachers of SD Metta Maitreya Pekanbaru, so the sample was 24 people. The data collection instrument was in the form of a questionnaire or questionnaire. The validity and reliability of the questionnaire on performance, organizational commitment, and organizational culture have been tested. The data normality test was carried out by the Kolmogorov Smirnov test. The data analysis used was multiple correlation analysis using a level of $\alpha=0.05$. The results of data analysis show that there is a significant relationship between Organizational Commitment (X1) and Organizational Culture (X2) and Teacher Performance $(\mathrm{Y})$ together with the regression equation $\mathrm{Y}^{\wedge}=81.388+0.295 \mathrm{X} 1+$ $0.466 \mathrm{X} 2$, the correlation coefficient is 0.570 . The results of this study are expected to be useful for improving the performance, organizational commitment and organizational culture of SD Metta Maitreya Pekanbaru. The conclusion of this study shows that performance can be increased through increasing organizational commitment and organizational culture simultaneously.
Abstrak: Penelitian ini dilatarbelakangi oleh kinerja guru SD Metta Maitreya masih tergolong belum professional, dipeorleh nilai di bawah KKM, dan kurangnya komitmen organisasi guru terhadap sekolah, serta kurangnya tanggungjawab guru dalam bekerja. Oleh karena itu, penelitian ini bertujuan untuk mengetahui hubungan antara komitmen organisasi dan budaya organisasi dengan kinerja guru SD Metta Maitreya Pekanbaru. Metode penelitian yang digunakan adalah metode survei dengan teknik korelasional. Populasi penelitian adalah 24 guru SD Metta Maitreya Pekanbaru sehingga sampelnya 24 orang. Instrumen pengumpulan data berbentuk kuisioner atau angket. Angket kinerja, komitmen organisasi, dan budaya organisasi sudah diuji validitas dan reliabilitas. Pengujian normalitas data dilakukan dengan uji Kolmogorov Smirnov. Analisis data yang digunakan adalah analisis korelasi ganda dengan menggunakan taraf $\alpha=$ 0,05 . Hasil analisis data menunjukkan bahwa terdapat hubungan yang signifikan antara Komitmen Organisasi $\left(\mathrm{X}_{1}\right)$ dan Budaya Organisasi $\left(\mathrm{X}_{2}\right)$ dengan Kinerja Guru $(\mathrm{Y})$ secara bersama-sama dengan persamaan regresi $\mathrm{Y}^{\wedge}=81,388+0,295 \mathrm{X} 1$ $+0,466 \mathrm{X} 2$, koefesien korelasi sebesar 0,570. Hasil penelitian ini diharapkan berguna untuk perbaikan kinerja, komitmen organisasi dan budaya organisasi SD Metta Maitreya Pekanbaru. Kesimpulan penelitian ini menunjukkan bahwa kinerja dapat ditingkatkan melalui peningkatan komitmen organisasi dan budaya organisasi secara simultan.

\section{Yadi Sutikno}

Program Studi Pendidikan Keagamaan Buddha

Sekolah Tinggi Agama Buddha Maitreyawira, Pekanbaru

E-mail: stabmaitreyawira@gmail.com 


\section{LATAR BELAKANG}

Guru memegang peranan penting dalam dunia pendidikan. Sebagai guru mempunyai tugas dan tanggung jawab untuk mendidik, mengajar, melatih, dan membimbing peserta didik untuk mencapai prestasi di sekolah sehingga dapat menjadi insan yang mulia. Hal ini perlu perjuangan kita bersama. Mutu pendidikan di sekolah juga ditentukan oleh guru. Tinggi dan rendahnya mutu pendidikan di sekolah juga ditentukan oleh guru. Jika ingin mutu pendidikan di sekolah tinggi maka guru harus memiliki kinerja yang baik. Dengan demikian, mutu pendidikan di sekolah akan dapat meningkat dan baik. Salah satu sekolah yang bercirikan Buddhis yang terdapat di Kota Pekanbaru yaitu SD Metta Maitreya. Melalui SD Metta Maitreya diharapkan dapat dididik Generasi Muda Buddhis yang memiliki karakter yang mulia. Hal ini tentu yang ikut menentukannya adalah guru dan salah satu yang sangat menentukan suksesnya pendidikan peserta didik di sekolah adalah kinerja guru.

Menurut Mangkunegara (2009) mengatakan bahwa kinerja adalah hasil kerja secara kualitas dan kuantitas yang dicapai oleh seseorang pegawai dalam melaksanakan tugasnya sesuai dengan tanggung jawab yang diberikan kepadanya. Persamaan kedua pendapat di atas adalah sama-sama menjelaskan bahwa wujud dari kinerja adalah perbuatan seseorang. Sependapat dengan Irawan, Wibowo (2007) menyatakan bahwa kata kinerja dinyatakan sebagai Performance. George dan Jones (2005) menyatakan bahwa Kinerja adalah evaluasi perilaku seseorang menyelesaikan pekerjaan. Pendapat yang hampir sama dengan Hornby dan Kanfer, juga dinyatakan oleh Nawawi (2006) bahwa Kinerja adalah apa yang dikerjakan atau tidak dikerjakan oleh seseorang dalam melaksanakan tugas-tugas pokoknya. Berdasarkan beberapa pendapat tentang kinerja tersebut, maka dapat dipahami bahwa kinerja merupakan evaluasi hasil kerja seseorang dalam menyelesaikan pekerjaan. Ini berarti harus ada instrumen yang digunakan untuk melakukan evaluasi terhadap hasil kerja yang telah dilakukan oleh seseorang. Dengan adanya evaluasi tersebut maka akan dapat dilakukan tindak lanjut terhadap hasil kerja tersebut.

Namun kenyataannya, hasil observasi menunjukkan kinerja guru SD Metta Maitreya masih tergolong belum profesional. Ini ditandai dari pengamatan yang dilakukan pada 20 Februari 2020 bahwa masih terdapat beberapa peserta didik yang belum memahami pelajaran di sekolah. Hasil dari kurangnya pemahaman peserta didik terhadap pelajaran sekolahnya adalah tidak mampunya siswa mengerjakan Pekerjaan Rumah yang diberikan oleh guru. Fenomena tersebut harus dicarikan solusinya oleh guru. Fenomena lainnya yang terlihat adalah masih adanya beberapa siswa di SD Metta Maitreya yang masih remedial atau mendapatkan nilai di bawah KKM (kriteria ketuntasan minimal) pada tes yang diberikan oleh guru. Padahal seharusnya nilai siswa harus mencapai nilai KKM dan kalau dapat di atas nilai KKM. Dari dua fenomena di atas, kinerja guru di atas masih belum professional maka hal ini tentu perlu dicarikan solusinya agar kinerja guru dapat profesional. Berdasarkan wawancara yang dilakukan pada tanggal 20 Juni 2020, didapatkan fenomena kurangnya komitmen organisasi guru terhadap sekolah. Ini ditandai dengan adanya guru yang belum professional saat bekerja sebagai guru di SD Metta Maitreya. Guru yang memiliki komitmen organisasi yang baik akan bekerja dengan professional. Berdasarkan pengamatan yang dilakukan pada tanggal 20 Juni 2020, didapatkan fenomena kurangnya tanggung jawab guru dalam bekerja. Ini ditandai dengan adanya guru yang tidak mengingatkan siswa yang belum mengerjakan tugas yang diberikannya. Seharusnya guru mengingatkan siswa juga merupakan budaya yang baik agar siswa dapat ingat untuk mengerjakan PRnya. Seharusnya guru tersebut mengingatkan siswa tersebut dan mengadakan komunikasi agar siswa tersebut dapat diingatkan dan mengerjakan tugas yang diberikan. Ini tentu juga harus dicarikan solusinya agar budaya organisasi guru dapat baik.

Berdasarkan permasalahan tersebut, perlu dilakukan upaya untuk meningkatkan kinerja guru, salah satunya adalah komitmen organisasi. Meyer dan Allen (1997) menyatakan bahwa Komitmen organasi mencerminkan tentang tingkat pemahaman seseorang individu mengindentifikasi organisasi dan tujuannya. Kemudian Luthan (2002) mengartikan komitmen organisasi dalam tiga pengertian yaitu: 1) suatu kekuatan sikap sekaligus keputusan yang menjadi bagian organisasi; 2) suatu keinginan atau kehendak untuk mewujudkan kinerja tinggi sebagai bagian yang harus ditumbuhkembangkan 
dalam organisasi; dan 3) suatu keyakinan yang diterima sebagai nilai sekaligus tujuan yang harus dicapai oleh organisasi. Komitmen organisasi adalah suatu keinginan seseorang untuk menwujudkan kinerja yang baik di dalam organisasi. Dengan adanya suatu keinginan tersebut maka akan membawa keuntungan yang baik bagi organisasi tersebut. Hal tersebut juga diperkuat oleh penelitian-penelitian sebelumnya yang menyatakan bahwa terdapat hubungan yang signifikan budaya organisasi dengan kinerja (Putriana, et.al., 2015). Hal yang sama juga dilakukan oleh Nugroho dan Tri Haryanto (2015) yang juga mengatakan bahwa ada hubungan komitmen organisasi dengan kinerja.

Selain factor komitmen organisasi, factor lain yang dapat mempengaruhi kinerja guru adalah budaya organisasi. Wirawan (2007) menyatakan bahwa Budaya Organisasi adalah norma, nilai-nilai, asumsi, budaya organisasi, filsafat, kebiasaan organisasi, yang dikembangkan dalam kurun waktu lama oleh pendiri, pemimpin, dan anggota organisasi yang disosialisasikan dan diajarkan kepada anggota baru serta diterapkan dalam aktivitas organisasi sehingga mempengaruhi pola pikir, sikap, dan perilaku anggota organisasi dalam memproduksi produk, melayani konsumen, dan mencapai tujuan organisasi. Kemudian Robbins (2001) menyatakan bahwa budaya organisasi adalah suatu sistem makna bersama yang dianut oleh anggota-anggota yang membedakan organisasi tersebut dengan organisasi-organisasi lain. Hasil penelitian juga menunjukkan bahwa budaya organisasi memiliki hubungan dengan kinerja guru (Mihsan, 2012), (Fithtri, 2018).

Berdasarkan teori dan beberapa hasil penelitian di atas, bahwa artikel ini mengusulkan bahwa komitmen organisasi dan budaya organisasi kemungkinan akan mampu meningkatkan kinerja mereka. Dasar pemikirannya bahwa guru yang memiliki komitmen yang tinggi akan memberikan usaha yang maksimal secara sukarela untuk kemajuan organisasi, berpartisipasi, dan terlibat aktif untuk memajukan organisasi, serta bertanggungjawab terhadap tugas yang dipercayakan kepadanya. Marni mengatakan bahwa budaya organisasi akan mampu menumbuhkan kemauan yang kuat dalam melaksanakan tugas-tugas tersebut (Rita, et.al., 2020). Berdasarkan teori dan penelitian-penelitian di atas, masalah kinerja guru SD Metta Maitreya dapat diselesaikan dengan meningkatkan komitmen organisasi dan budaya organisasi. Kemudian untuk pengujian secara penelitian maka akan dilakukan penelitian untuk menguji teori yang telah dijelaskan di atas. Diharapkan hasil penelitian yang dilakukan juga sama dengan teori yang telah dijelaskan di atas.

Berdasarkan beberapa permasalahan yang telah dijelaskan di atas maka peneliti tertarik untuk menyelesaikan masalah tersebut dengan melakukan penelitian yang berjudul "Hubungan antara Komitmen Organisasi dan Budaya Organisasi dengan Kinerja Guru SD Metta Maitreya Pekanbaru”.

\section{METODE}

Metode yang digunakan dalam penelitian pendidikan ini adalah metode survei dengan teknik korelasional yang dilakukan di SD Metta Maitreya mulai dari Juni sampai dengan 31 Agustus 2020. Populasi dalam penelitian ini adalah seluruh guru SD Metta Maitreya yang berjumlah 24 orang. Oleh karena jumlah guru SD Metta Maitreya kurang dari 100 orang maka semua anggota populasi dijadikan sampel sehingga sampel dalam penelitian ini adalah 24 orang guru. Hal ini sejalan dengan pendapat Arikunto (2010) mengatakan bahwa apabila populasi penelitian berjumlah kurang dari 100, maka sampel yang diambil adalah semuanya. Instrumen dan Teknik pengumpulan data yang digunakan dalam penelitian ini adalah kuisioner yang berjumlah 39 butir pertanyaan untuk variable kinerja guru, 25 butir pernyataan untuk variable komitmen organisasi, dan 28 butir pernyataan untuk variable budaya organisasi. Seluruh butir pertanyaan yang digunakan dalam penelitian telah melalui tahap uji validitas dan reliabilitas. Hasil pengujian tersebut menunjukkan masing-masing butir pertanyaan dinyatakan valid dan reliabel. Setelah data terkumpul, selanjutnya dianalisis menggunakan uji korelasi ganda dengan bantuan SPSS versi 23.00 for Windows. 
142 Instructional Development Journal (IDJ), Vol. 3, No. 3, Desember 2020, Hal. 139-146

\section{HASIL DAN PEMBAHASAN}

\section{Hasil Penelitian}

Analisis data untuk menguji hipotesis penelitian dilakukan dengan menggunakan analisis statistik parametrik, yaitu analisis regresi, korelasi sederhana, dan korelasi ganda. Untuk menggunakan analisis statistik parametrik tersebut maka perlu dilakukan pengujian persyaratan analisis yaitu dengan uji normalitas. Berikut ini hasil uji normalitas terhadap kinerja guru, komitmen organisasi, dan budaya organisasi dengan menggunakan bantuan SPSS 23.00 for Windows.

Tabel 1. Hasil Uji Normalitas Kinerja, Komitmen Organisasi, dan Budaya Organisasi

\begin{tabular}{llr}
\hline N & & Unstandardized Residual \\
\hline Normal Parameters $^{\mathrm{a}}$ & Mean & 24 \\
& Std. Deviation & .0000000 \\
Most Extreme Differences & Absolute & 8.26757246 \\
& Positive & .108 \\
& Negative & .084 \\
Kolmogorov-Smirnov Z & &. .108 \\
Asymp. Sig. (2-tailed) & & .527 \\
\hline
\end{tabular}

Berdasarkan hasil pengujian dengan menggunakan SPSS 16, maka diperoleh hasil uji One Sample Kolmogrov Smirnov yang sudah dirangkum dalam tabel 9 di atas. Berdasarkan tabel di atas, dapat dilihat bahwa nilai signifikansi Asymp. Sig. (2-tailed) sebesar 0,944>0,05. Maka sesuai dengan dasar pengambilan keputusan dalam uji normalitas Kolmogrov Smirnov di atas, dapat disimpulkan bahwa data sudah berdistribusi normal. Dengan demikian, asumsi atau persyaratan dalam model regresi sudah terpenuhi. Setelah memenuhi persyaratan uji normalitas, selanjutnya dilakukan uji hipotesis yang diajukan, yaitu terdapat hubungan yang signifikan antara komitmen organisasi dan budaya organisasi secara bersama-sama dengan kinerja guru. Hasil perhitungan kekuatan hubungan antara komitmen organisasi $\left(\mathrm{X}_{1}\right)$ dan budaya organisasi $\left(\mathrm{X}_{2}\right)$ dengan kinerja guru $(\mathrm{Y})$ ditunjukkan oleh koefisien korelasi ganda $(\mathrm{R})$ sebesar 0,570 (dapat dilihat pada tabel 24 di bawah ini). Ini memberikan arti bahwa hubungan antara komitmen organisasi dan budaya organisasi dengan kinerja guru adalah cukup kuat. Sebagaimana dinyatakan tentang pedoman untuk memberikan penjelasan koefisien korelasi yang tertera pada tabel 25 di bawah. Selain itu, dapat dilihat bahwa tingkat Sig. F Change pada tabel di bawah sebesar 0,016 0,05 yang artinya $\mathrm{H}_{0}$ ditolak dan $\mathrm{H}_{\mathrm{a}}$ diterima sehingga komitmen organisasi dan budaya organisasi berpengaruh secara bersama-sama atau simultan dengan kinerja guru.

Tabel 2. Hasil Uji Koefisien Korelasi antara Komitmen Organisasi $\left(\mathbf{X}_{1}\right)$ dan Budaya Organisasi $\left(\mathbf{X}_{2}\right)$ dengan Kinerja Guru (Y)

\section{Model Summary}

\begin{tabular}{|c|c|c|c|c|c|c|c|}
\hline \multirow[b]{2}{*}{ Model } & \multirow[b]{2}{*}{$\mathrm{R}$} & \multirow[b]{2}{*}{$\begin{array}{c}\mathrm{R} \\
\text { Square }\end{array}$} & \multirow[b]{2}{*}{$\begin{array}{l}\text { Adjusted R } \\
\text { Square }\end{array}$} & \multirow[b]{2}{*}{$\begin{array}{l}\text { Std. Error of the } \\
\text { Estimate }\end{array}$} & \multicolumn{3}{|c|}{ Change Statistics } \\
\hline & & & & & $\begin{array}{l}\text { R Square } \\
\text { Change }\end{array}$ & $\begin{array}{c}F \\
\text { Change }\end{array}$ df1 df2 & $\begin{array}{c}\text { Sig. F } \\
\text { Change }\end{array}$ \\
\hline 1 & $.570^{\mathrm{a}}$ & .324 & .260 & 8.652 & .324 & $5.042 \quad 2 \quad 21$ & .016 \\
\hline
\end{tabular}

Hasil perhitungan koefisien determinasi ( $R$ Square) sebesar 0,324 atau 32,4\%. Ini berarti bahwa sebesar 32,4\% variansi komitmen organisasi dan budaya organisasi dapat dijelaskan oleh kinerja guru melalui persamaan regresi $\widehat{Y}=81,388+0,295 \mathrm{X}_{1}+0,466 \mathrm{X}_{2}$. sedangkan sisanya sebesar $67,6 \%$ dipengaruhi oleh variabel-variabel lain yang tidak diteliti dalam penelitian ini. 
Pola hubungan ketiga variabel penelitian dapat digambarkan sebagai berikut:

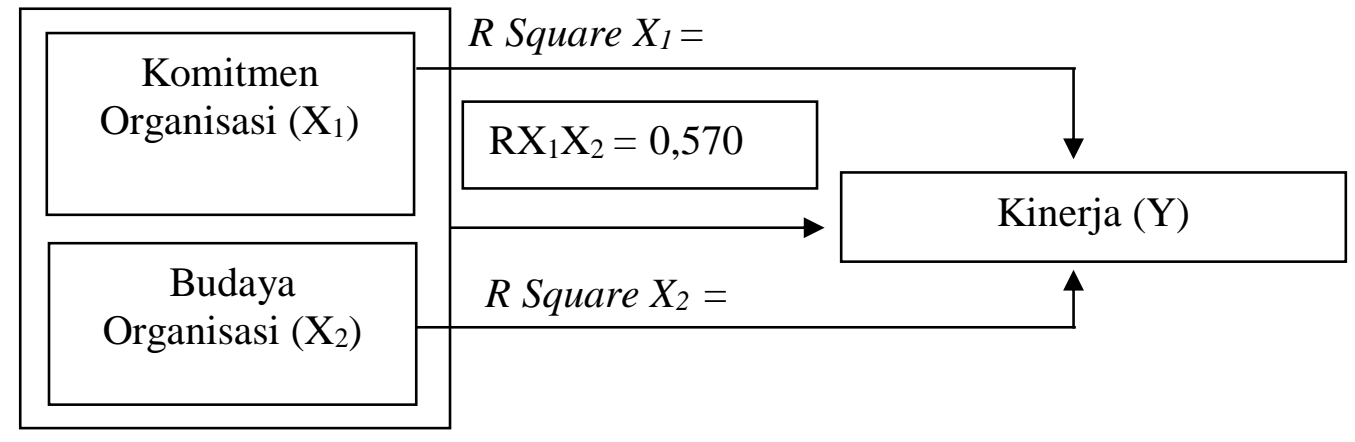

Gambar 1. Pola Hubungan antar Variabel Penelitian

\section{Pembahasan}

Untuk hubungan yang terjadi antara komitmen organisasi dan budaya organisasi secara bersamasama dengan kinerja guru, koefisien korelasi yang terbentuk yaitu sebesar 0,570 yang mengartikan hubungan antara komitmen organisasi dan budaya organisasi secara bersama - sama dengan kinerja guru adalah cukup kuat. Dari hasil perhitungan koefisien determinasi $R$ Square sebesar 0,324 atau $32,4 \%$. Ini berarti bahwa 32,4\% variabel komitmen organisasi dan budaya organisasi dapat dijelaskan melalui persamaan regresi $\widehat{Y}=81,388+0,295 X_{1}+0,466 X_{2}$. Persamaan regresi $\widehat{Y}=81,388+0,295 X_{1}+$ $0,466 \mathrm{X}_{2}$ mempunyai arti bahwa setiap peningkatan satu satuan skor komitmen organisasi dan budaya organisasi secara bersama - sama dapat meningkatkan skor kinerja guru masing-masing 0,295 dan 0,466 pada konstanta 81,388. Berdasarkan hasil dari $F_{\text {hitung }}=5,042>F_{\text {tabel }}=3,46680$, dengan taraf signifikansi 0,05, maka $\mathrm{H}_{0}$ ditolak dan $\mathrm{H}_{\mathrm{a}}$ diterima yang menjelaskan bahwa variabel independen, yaitu terdapat hubungan yang signifikan antara komitmen organisasi $\left(\mathrm{X}_{1}\right)$ dan budaya organisasi $\left(\mathrm{X}_{2}\right)$ secara bersamasama atau simultan dengan kinerja guru $(\mathrm{Y})$.

Menurut Geert Hofstede juga menyatakan bahwa budaya terdiri dari mental program bersama yang mensyaratkan respons individual pada ligkungannya (Wibiwo, 2010). Defenisi tersebut mengundang makna bahwa kita melihat budaya dalam perilaku sehari-hari, tetapi dikontrol oleh mental program yang ditanamkan sangat dalam. Budaya bukan hanya perilaku di permukaan, tetapi sangat dalam di tanamkan dalam diri kita masing masing. Temuan penelitian ini menunjukkan bahwa untuk mengoptimalkan budaya organisasi di madrasah maka guru harus memiliki kesungguhannya dalam pekerjaannya. Budaya organisasi di madrasah yang telah dirasakan oleh guru tampak ketika pekerjaann yg dilakukannya dengan senang hati. Menurut Undang- undang Republik Indonesia No. 14 Tahun 2005 tentang guru dan dosen "Guru adalah pendidik professional dengan tugas utama mendidik, mengajar, membimbing, mengarahkan, melatih, menilai, dan mengevaluasi peserta didik pada pendidikan usia dini, pendidikan dasar, dan pendidikan menengah. Oleh karena itu, seorang guru harus benar-benar menjalankan ilmunya demi kepentingan orang banyak. Guru harus memiliki alasan mendasar bahwa guru harus menjadi pekerja profesional dalam berkomitmen.

Menurut N.J Allen dan J.P Meyer mengatakan komitmen dapat juga berarti penerimaan yang kuat individu terhadap tujuan dan nilai- nilai organisasi, dan individu berupaya serta berkarya dan memiliki hasrat yang kuat untuk tetap bertahan di organisasi tersebut (Wijaya, 2016). Guru memiliki tanggung jawab besar dalam proses tranformasi ilmu kepada peserta didik. Guru dituntut harus memiliki komitmen, mampu mengajar dengan baik, mampu merancang, memilih bahan belajar, dan strategi pembelajaran yang dapat menyesuaikan dengan keadaan peserta didik, serta mampu mengelola proses pembelajaran yang dapat menyesuaikan dengan keadaan peserta didik, serta mampu mengelola proses pembelajaran dan melakukan evaluasi untuk mengukur penguasaan hasil belajar, serta sebagai pendidik guru bertugas membimbing, membina, dan mengarahkan siswanya ke arah lebih aktif, kreatif dan mandiri. Dengan adanya hal ini guru harus memiliki komitmen dengan adanya kepercayaan, keterlitaban dengan setiap orang yang berada di dalam lingkungan sekolah dan loyalitas terhadap 
144 Instructional Development Journal (IDJ), Vol. 3, No. 3, Desember 2020, Hal. 139-146

madrasah. Berhubungan dengan kedua hal tersebut akan memberikan dampak kepuasan kinerja guru yang di rasakan oleh guru baik yang berasal dari dalam dirinya maupun berasal dari luar diri guru tersebut akan menentukan tingkat komitmen kerja guru di madrasah.

Wahyuni, dkk., (2014) dalam penelitiannya dengan judul Influence of Organizational Commitment, Transactional Leadership, and Servant Leadership to the Work Motivation, Work Satisfaction and Work Performance of Teachers at Private Senior High Schools in Surabaya menemukan bahwa komitmen organisasi berpengaruh terhadap kinerja guru. Selanjutnya, Ade, dkk., (2013) dalam penelitiannya dengan judul The Influence of Organizational Commitment and Individual Competence on Teacher Performance menemukan bahwa komitmen organisasi berpengaruh positif dan signifikan terhadap kinerja guru. Mutmainah (2013) dalam jurnal internasional dengan judul Organizational Culture, Leadership Style Influence on Organizational Commitment and Performance of Teacher menemukan bahwa budaya organisasi berpengaruh positif dan signifikan terhadap kinerja guru di sekolah menengah di Uganda. Kemudian, Ahmad, dkk., (2019) dalam Hasanuddin Journal of Applied Business and Entrepreneurship menemukan hasil bahwa budaya organisasi mempunyai pengaruh positif dan signifikan terhadap kinerja guru. Dengan demikian, semakin tinggi komitmen organisasi dan budaya organisasi maka akan semakin tinggi kinerja guru.

\section{SIMPULAN DAN SARAN Simpulan}

Berdasarkan pengujian hipotesis dan pembahasan hasil penelitian, diperoleh kesimpulan bahwa Terdapat hubungan yang signifikan antara komitmen organisasi $\left(\mathrm{X}_{1}\right)$ dan budaya organisasi $\left(\mathrm{X}_{2}\right)$ secara bersama-sama dengan kinerja guru (Y) SD Metta Maitreya. Komitmen organisasi dan budaya organisasi secara bersama-sama dapat menentukan dan memberikan kontribusi sebesar 0,324 atau 32,4\% terhadap kinerja guru. Artinya 32,4\% kinerja guru dapat ditingkatkan melalui komitmen organisasi dan budaya organisasi, sedangkan sisanya sebesar 67,6\% dapat ditingkatkan melalui variabel - variabel lain yang tidak diteliti dalam penelitian ini. Berdasarkan penjelasan di atas, diketahui bahwa hipotesis penelitian yang diajukan dapat diterima, yaitu komitmen organisasi $\left(\mathrm{X}_{1}\right)$ dan budaya organisasi $\left(\mathrm{X}_{2}\right)$ mempunyai hubungan yang signifikan secara simultan (bersama-sama) dengan kinerja guru (Y) SD Metta Maitreya. Dengan demikian, kinerja Guru SD Metta Maitreya dapat ditingkatkan melalui peningkatan komitmen organisasi dan budaya organisasi.

\section{Saran}

Berdasarkan hasil penelitian dan pembahasan di atas maka berikut ini diberikan saran dalam penelitian ini yaitu: 1) guru SD Metta Maitreya harus dapat membuat siswa dapat memahami materi pelajaran sehingga dapat mengerjakan PR yang diberikan oleh guru; 2) guru SD Metta Maitreya harus berusaha agar nilai siswa berada di atas KKM untuk setiap mata pelajaran; 3) guru SD Metta Maitreya harus berusaha profesional saat bekerja; 4) guru SD Metta Maitreya harus bertanggung jawab saat bekerja; dan 5) masalah dalam penelitian ini sudah selesai yaitu dengan meningkatkan komitmen organisasi dan budaya organisasi agar kinerja guru dapat meningkat.

\section{DAFTAR RUJUKAN}

Wijaya, C., \& Rifa'I, M. (Ed). 2016. Dasar-Dasar Manajemen. Medan: Perdana Publishing. Wibowo. (2011). Manajemen Kinerja. Jakarta: PT. Raja Grafindo Persada.

Hayati, R., Arafat, Y., \& Sari, A. P. (2020). Pengaruh Komitmen Organisasi dan Motivasi Kerja terhadap Kinerja Guru. JMKSP (Jurnal Manajemen, Kepemimpinan, dan Supervisi Pendidikan), 5(2). 
Farid, A., Haerani, S., Hamid, N., \& Reni, A. (2019). Pengaruh Budaya Organisasi, Komitmen Organisasi dan Kepuasan Kerja terhadap Kinerja Guru Sekolah Menengah Atas di Makassar. Hasanuddin Journal of Applied Business and Entrepreneurship, 2(2), 89-99.

Ardiana, T. E. (2017). Pengaruh motivasi kerja guru terhadap kinerja guru akuntansi SMK di Kota Madiun. Jurnal Akuntansi dan Pajak, 17(02).

Arikunto, S. (2010). Prosedur Penelitian Suatu Pendekatan Praktik (edisi revisi 2010). Jakarta: Rineka Cipta.

Armstrong, M. (1994). Performance management key strategies and practical guidelines. Saxon Graphics Ltd, Derby.

Atmazaki. (2013). Penilaian Alternatif dalam Pembelajaran Bahasa Indonesia. Padang: UNP Press.

Colquitt, J., Lepine, J. A., Wesson, M. J., \& Gellatly, I. R. (2011). Organizational behavior: Improving performance and commitment in the workplace (Vol. 375). New York, NY: McGraw-Hill Irwin.

Fithri, F. (2018). Hubungan antara Budaya Organisasi dengan Kinerja Guru di MTs Negeri 1 Bandar Lampung (Doctoral dissertation, UIN Raden Intan Lampung).

Irawan, P. (2003). Pengembangan Sumber Daya Manusia. Jakarta: STIA LAN Press.

George, J. M., Jones, G. R., \& Sharbrough, W. C. (2005). Understanding and managing organizational behavior. Upper Saddle River, NJ: Pearson Prentice Hall.

Luthans, F. (2002). Organizational Behavior. New York: McGraw-Hill Company.

Mangkunegara, A. P., \& Prabu, A. (2009). Manajemen Sumber Daya Manusia. Bandung: PT. Remaja Rosdakarya.

Meyer, J. P., \& Allen, N. J. (1997). Commitment in the workplace: Theory, research, and application. Sage.

Mishan. (2014). Pengaruh Motivasi Kerja Guru Dan Budaya Organisasi terhadap Kinerja Guru SMA Negeri di Kota Sibolga. Jurnal Bisnis dan Manajemen Eksekutif, Vol. 1 No. 2.

Muliyardi. (2002). Strategi Pembelajaran Matematika. Padang: FMIPA UNP.

Mutmainah, E. A. T. (2013). Noermijati. 2013 “. Organizational Culture, Leadership Style Influence on Organizational Commitment and Performance of Teachers.”. International Journal of Business and Behavioral Sciences, 3(10), 54-65.

Nawawi, H. (2006). Evaluasi dan Manajemen Kinerja di Lingkungan Perusahaan dan Industri. Yogyakarta: Gadjah Mada University Press.

Nugroho, A. P., \& Haryanto, A. T. (2019). The Role of Job Characteristics and Professional Commitment to Tenure and Performance (Study of Teachers in Public High Schools in Solo Raya). Journal of Indonesian Science Economic Research, 1(1), 26-31.

Pasolong, H. (2008). Kepemimpinan Birokrasi. Bandung: Alfabeta.

Peraturan Menteri Pendidikan Nasinal No. 16 Tahun 2007 tentang Standar Kualifikasi Akademik dan Kompetensi Guru.

Purwanto. (2011). Evaluasi Hasil Belajar. Yogyakarta: Pustaka Pelajar.

Putriana, L., Umar, H., \& Riady, H. (2015). The impact of organizational culture on job satisfaction, organizational Commitment and job Performance: Study on Japanese Motorcycle Companies in Indonesia. Int J Edu Res, 3, 103-14.

Rees, D., \& McBain, R. (2007). People Management: Teori dan Strategi (Tantangan dan Peluang). Jakarta: Penerbit Kencana, Terjemahan. 
146 Instructional Development Journal (IDJ), Vol. 3, No. 3, Desember 2020, Hal. 139-146

Riduwan. (2010). Metode dan Teknik Menyusun Tesis. Bandung: Alfabeta.

Schuler, R. S., \& Jackson, S. E. (1997). Manajemen Sumber Daya Manusia Menghadapi Abad ke 21. Jakarta: Erlangga.

Sudaryanto. (1993). Metode dan Aneka Teknik Analisis Bahasa: Pengantar Penelitian Wahana Kebudayaan secara Linguistis. Yogyakarta: Duta Wacana University Press.

Razak, A. (2008). Riset Pengajaran: Deskripsi, Eksposisi, dan Argumentasi. Pekanbaru: Autografika.

Wahyuni, D. U., Christiananta, B., \& Eliyana, A. (2014). Influence of organizational commitment, transactional leadership, and servant leadership to the work motivation, work satisfaction and work performance of teachers at private senior high schools in Surabaya. Educational Research International, 3(2), 82-96.

Wibowo. (2007). Manajemen Kinerja. Jakarta: Rajawali Pers.

Wirawan. (2007). Budaya dan Iklim Organisasi: Teori dan Aplikasi dan Penelitian. Jakarta: Salemba Empat.

Wirawan. (2014). Kepemimpinan, Teori, Psikologi, Perilaku Organisasi, Aplikasi dan Penelitian. Jakarta: Rajawali Pers.

Robbins, S. P., \& Judge, T. A. (2001). Organizational Behavior, $9^{\text {th }}$ Edition. Halida, Sartika, D.(penerjemah). Prinsip-prinsip Perilaku Organisasi. Jakarta: Erlangga. 